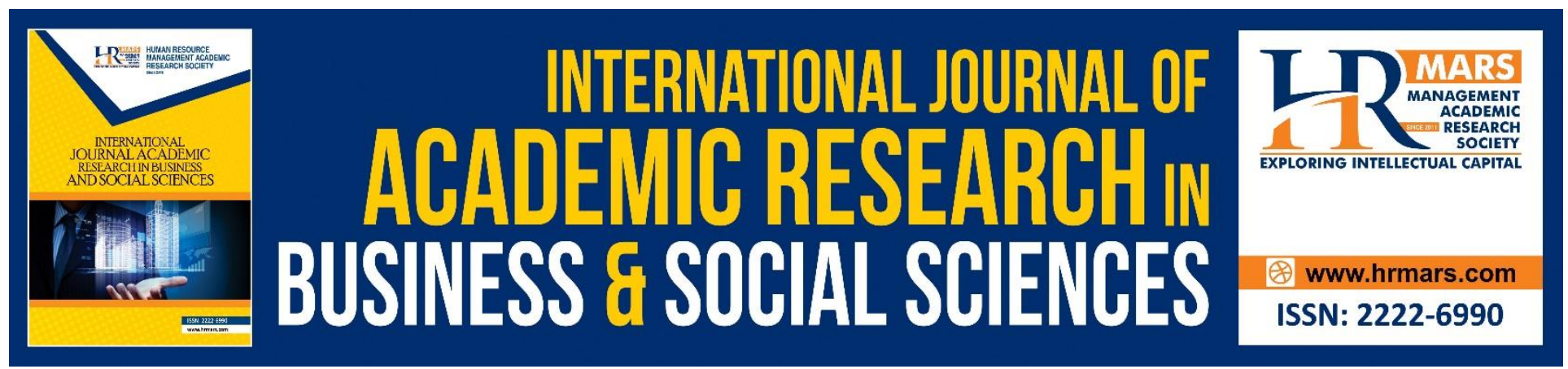

\title{
Altruistic and Egoistic Prosocial Behaviors among Orang Asli Adolescents: Its Relations to Attachments and Prosocial Value
}

Aini Azeqa Ma'rof, Hanina H. Hamsan

To Link this Article: http://dx.doi.org/10.6007/IJARBSS/v10-i16/8292

DOI:10.6007/IJARBSS/v10-i16/8292

Received: 10 October 2020, Revised: 25 October 2020, Accepted: 15 November 2020

Published Online: 29 November 2020

In-Text Citation: (Ma'rof \& Hamsan, 2020)

To Cite this Article: Ma'rof, A. A., \& Hamsan, H. H. (2020). Altruistic and Egoistic Prosocial Behaviors among Orang Asli Adolescents: Its Relations to Attachments and Prosocial Value. International Journal of Academic Research in Business and Social Sciences, 10(16), 58-72.

\section{Copyright: (c) 2020 The Author(s)}

Published by Human Resource Management Academic Research Society (www.hrmars.com)

This article is published under the Creative Commons Attribution (CC BY 4.0) license. Anyone may reproduce, distribute, translate and create derivative works of this article (for both commercial and non-commercial purposes), subject to full attribution to the original publication and authors. The full terms of this license may be seen

at: http://creativecommons.org/licences/by/4.0/legalcode

Special Issue: Youth and Community Wellbeing: Issues, Challenges and Opportunities for Empowerment V2, 2020, Pg. 58 - 72

Full Terms \& Conditions of access and use can be found at http://hrmars.com/index.php/pages/detail/publication-ethics 


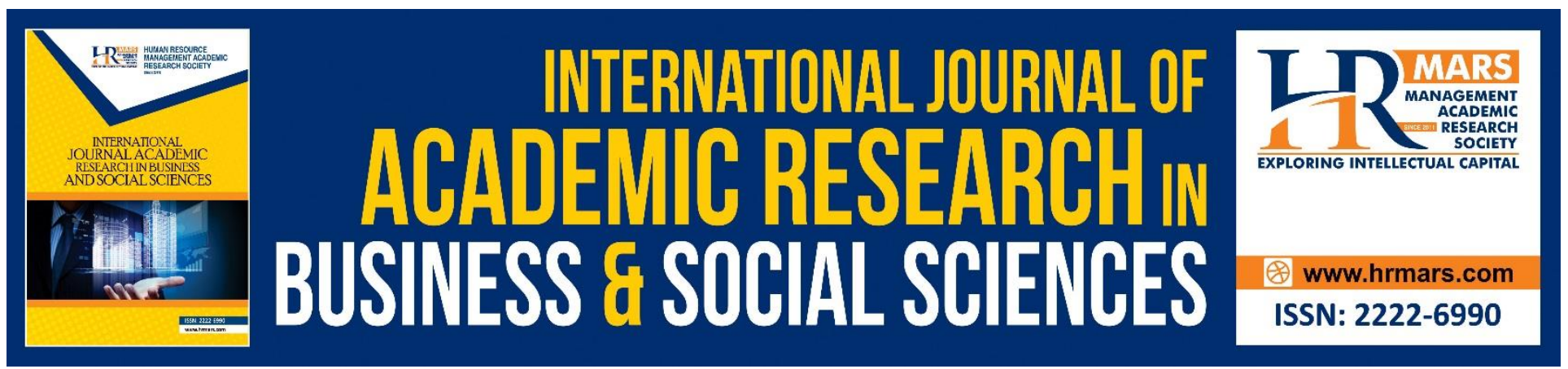

\title{
Altruistic and Egoistic Prosocial Behaviors among Orang Asli Adolescents: Its Relations to Attachments and Prosocial Value
}

\author{
1,2Aini Azeqa Ma'rof, 1,2Hanina H. Hamsan \\ ${ }^{1}$ Institute for Social Science Studies, Putra Infoport, Universiti Putra Malaysia, \\ 43400 UPM Serdang, Selangor Darul Ehsan, Malaysia, ${ }^{2}$ Faculty of Human Ecology, Universiti Putra \\ Malaysia, 43400 Serdang, Selangor Darul Ehsan, Malaysia. \\ Email: azeqa@upm.edu.my, hanina@upm.edu.my
}

\begin{abstract}
Attachment theories postulate that attachment is crucial during adolescence and act as an important predictor to prosocial behavior. From attachment and prosocial value perspective, people develop the ability to empathize with others which is related to healthy functioning and positive helping behavior. This study therefore examine the relations between social attachments (i.e., parental, peer, school, and ethnic group attachments) and prosocial value (i.e., kindness) on the distinct type of prosocial behavioral tendencies (i.e., altruistic and egoistic prosocial behaviors). The study was conducted among the Orang Asli adolescents $(N=402)$ aged 14 years and 16 years from ten secondary schools in the states of Perak and Pahang and employed self-administered questionnaire. The results revealed that there were significant relationships between parental, peer and ethnic group attachments on altruistic and egoistic prosocial behavior tendencies. Significant relationship also was found on the relations between prosocial value and both prosocial behavior tendencies. However, there was no significant relationship for school attachment and both prosocial behavior tendencies. Findings from this study suggests that attachment to specific social group contribute to the distinct types of prosocial behavior tendencies, meanwhile, regardless of the types of prosocial behavior, it comes together with the kindness act. This study further discusses on the implication of attachment specifically among the Orang Asli in preserving their prosocial acts.
\end{abstract}

Keywords: Altruistic Prosocial Behavior, Egoistic Prosocial Behavior, Parental Attachment, Peer Attachment, Ethnic Group Attachment, Prosocial Value.

\section{Introduction}

Prosocial behavior refers to any action that is intended to benefit others, regardless of the actor's underlying intention(s) (Piliavin, Dovidio, Gaertner, \& Clark, 1981). This behavior is basically involves any action that commonly perceived as good from a societal perspective, such as sharing, helping, 
volunteering, showing social solidarity, and cooperating (Brief \& Motowild, 1986). These terms have been used interchangeably with reference to prosocial behavior and closely relate positively to a range of psychological processes that benefit both individuals and society (Eisenberg \& Mussen, 1989). However, there is substantial variation in the extent to which people act prosocially within and across societies (House, Silk, Henrich, et al., 2013). Therefore, understanding the sources of this variability may provide insight into the forces that foster altruistic or egoistic prosocial intentions.

Studies in prosocial behavior generally did not distinguish the differing types of prosocial behaviors (Carlo et al., 2003). Previous studies mainly measure prosocial behavior in general. Somehow, it is important to notify that one's intention to help might underlies by several intentions, for instance, due to emotional tights, in emergency, for reward or praise. According to Social Exchange Theory (Homans, 1958), help will be given depending on the interaction involved with the person. This theory argues that much of what a person does stems from the desire to maximize the rewards received and minimize the costs given. Thus, any help given to others mainly depends on the person's intention where help can be extended solely for the benefits of others (i.e., altruistic), but there may be also instances when help is given to gain reward or approval (i.e., egoistic).

Although global measures of prosocial behaviors might be useful for assessing general helping behavior in general, however, prosocial behaviors might be constructed as one aspect of social competence (Carlo et al., 2003). Thus, it is expected that there is different underlying intention for helping behavior for each individual. However, little focus was given on the multidimensional nature of prosocial behavior especially in ethnically diverse sample (Carlo et al., 2011). Therefore, this study could extend previous literature by examining prosocial behavior tendencies among the Orang Asli adolescents.

\section{Individual Motivations for Helping}

A protruding distinction in the helping literature concerns the difference between altruistic (otherfocused) and egoistic (self-focused) motivation (Penner, Dovidio, Piliavin, \& Schroeder, 2005). While egoistic motivation functionally related to the to preserve, maintain, or enhance one's own welfare, altruistic motivation is functionally related to the goal to preserve, maintain, or enhance the welfare of another being.

In explaining helping motivations from the psychological processes, with regard to egoistic motivations, research suggests two broad classes of motives (Dovidio, Piliavin, Schroeder, \& Penner, 2006). First, as a result of their learning experiences, people may perceive helping as an opportunity to gain material, social, and/or self-administered rewards through helping behavior, to avoid costs associated with not helping or both. Accordingly, people may actively seek to help a person in need because they may expect to receive financial compensation or social recognition, reciprocal help, and reduce the unease, guiltiness, or the shame feelings if they decided not to help. Second, people may also be motivated to help of a desire to reduce aversive arousal that leads to unpleasant feelings of seeing other person suffering. Seeing another person in distress typically elicits a vicarious physiological response in the observer including negative feelings such as distress, anxiety, or uneasiness (e.g., Eisenberg \& Fabes, 1991; Hoffman, 1981). Therefore, egoistic motivation relates to the ultimate goal of a person to improve (restore or preserve) his or her own welfare while improving the other's welfare which serves primarily as an instrumental means to do so. 
The psychological understanding of altruistic motivation, on the other hand, has been associated to the role of empathy in helping. According to Batson and Oleson (1991) as the pioneer of empathyaltruism hypotheses, this perspective involved perception of another person's need in conjunction with the quality of interpersonal relationship to that person (e.g., perceived self-other similarity, friendship, closeness) that evokes empathy. Empathy which is an emotional reaction including feelings of compassion, sympathy, and concern that amplify altruistic motivation. In line with this perspective, there have been many empirical demonstrations that feeling empathy for an individual in need increases helping even in situations in which helping is relatively demanding or even selfsacrificing (e.g., Batson \& Oleson, 1991; Davis, 1994).

\section{Social Cognitive Factors in Helping Motivations}

Previous studies suggests that altruism and egoism prosocial behaviors are influenced by different motivational systems. Specifically, although helping kin seems to involve a strong emotional component (Hamalainen \& Tanskanen, 2017), helping among non-kin seems to involve a careful processing of the individual transaction costs for helping which includes reciprocal helping (Waal \& Brosnan, 2006). Meanwhile, according to the evolutionary literature, self-other similarity may have been reliably correlated with actual kinship, thus, people may still unconsciously associate self-other similarity with genetic relatedness (e.g., Krebs, 2015; Park \& Schaller, 2005). This is to say that, when people recognize similarities between themselves and others, the other's welfare should thus become increasingly valued and this indirectly may lead to one's to act altruistically. This, in turn, should promote kin-like responses, specifically empathy and altruism, even to genetically unrelated individuals.

Self-other dissimilarity, by contrast, may function as a cue for non-relatedness. Specifically, helping dissimilar others may attributed to helping among non-kin in the expectation of reciprocity that guided by social exchange theory. Interesting support for this perspective comes from an experimental study by Park and Schaller (2005) whereby reciprocity relates to providing help to dissimilar others, meanwhile those that share a similar attitudes automatically associated with kinship cognitions that make the activation of altruistic helping. Moreover, additional analyses also provided evidence that the activation of kinship cognitions was significantly correlated with perceivers' willingness to help similar others. This overall shows that in order for people to act altruistically, the receivers must be someone that is perceived similar to the givers and vice versa.

\section{Attachment and Prosocial Value on Prosocial Behaviors}

Attachment and prosocial value are among the main indicators in contributing to prosocial acts (Mikulincer \& Shaver, 2015). Attachment which can be described as an enduring psychological connectedness between individuals posed an important role in fostering prosocial behaviors. According to attachment theory (Bowlby, 1980), adolescent with strong emotional bonds with their significant others help to form a secure attachment style which fosters socio-emotional and wellbeing. Social systems such as families (Yates \& Youniss, 1996), schools (Barr \& Higgins-D'Alessandro, 2007), peers (Hoorn, Dijk, Meuwese, Rieffe, \& Crone, 2017), and ethnic group (Armenta et al., 2010) could influence adolescent's helping behavior.

Specifically, socialization between parent and child often serve as a lifelong relationship (Lawford et al., 2005) that contribute towards the moral development and prosocial behavior. Parental 
attachment in particular that portrays by the secure, positive and warm relationship between parent and child, has been linked positively to prosocial behaviors in children and adolescents (Nie, Li, \& Vazsonyi, 2016). Meanwhile, for peer attachment, the success with which individuals establish and maintain positive peer relations may develop adolescents' socio-emotional aspects and adjustment across lifespan (Oldfield, Humphrey, \& Hebron, 2016). According to Carlo et al., (2011), peer relationship appears to play a significant role in the prosocial development of adolescents. In a study by Liable, Carlo, and Raffaelli (2000), the attachment security with peers was correlated with high empathy that brings to the supportive relationship with peers can enrich adolescent's care and responsibility toward others.

Meanwhile from the school context, it is the primary context for social interaction, cultivation of personal skills, and formation of peer groups, self-expression, and development of self (Henry \& Slater, 2007). According to Carlo et al., (1999), the environmental transition give a strong impact on student's prosocial and moral behavior. Moreover, schools that promote connectedness and cooperation in its environment could enhance the involvement in prosocial activities among adolescence (Eisenberg \& Eggum, 2009). Whereby for ethnic group attachment, it has been used interchangeably with ethnic identity. According to Tajfel (1981), pioneer of Social Identity Theory, ethnic identity is an individual's self-concept that derives from his or her knowledge of membership in a social group together with the value and emotional significance attached to that membership. Prior research revealed that feeling attached to one's ethnic group can facilitate positive behavioral outcomes among adolescents (Knight, Bernal, \& Carlo, 1995; Knight et al., 1993). This is also supported by a study conducted by Schwartz, Zamboanga, and Jarvis (2007) that shows individual that attached strongly to their ethnic group engaged in more cooperative and prosocial acts.

Earlier studies have also documented that kindness is the significant predictor for adolescents' prosocial behavior tendencies (Calderon-tena et al., 2011). This is supported by a study by Flook. Goldberg, Pinger, and Davidson (2015) where they found that adolescents who demonstrated exceptional commitments to care for others were particularly likely to describe themselves in terms of moral personality traits and goals and to articulate theories of self in which personal beliefs and philosophies were important. Meanwhile, a study revealed that adolescents who were more actively involved in community help activities reported closer agreement with parents and other social contact about the importance of moral values, for instance, the kindness value (Layous, Nelson, Oberle, Schonert-Reichl, \& Lyubomirsky, 2012). Overall, this shows the importance of social attachment and prosocial values that will foster prosocial acts regardless of one's intention.

\section{Prosocial Behavior Tendencies among Orang Asli}

Orang Asli which is the Malaysian aborigine is known as a well-valued culture that implements prosocial behavior acts such as sharing, cooperating and help each other within their tribes. They are also known as a Gemeinschaft community (Schaefer \& Lamm, 1998) which is characterized by a small community where members generally have similar backgrounds and life experiences, knowing the people in their tribes, and close social interaction between them. Having 18 sub-ethnic, this community nurtured the prosocial acts in order for them to survive especially in their settlement that most of it are in the remote area.

The Orang Asli community has been assessed as similar with respect to collectivism (Department of Orang Asli Affairs [JHEOA], 2008). Triandis (1996) argues that culture that emphasizes a collectivist 
orientation promotes and nurtures prosocial values and behaviors which consequently benefit the societal groups. On the other hand, individualistic societies emphasize competitiveness and self-gain. Although majority of this community still adheres to the more rural, traditional, and patriarchal pattern of living, there is an emerging coexistence of traditional and modern features among the Orang Asli community which may change the pattern and the way they valued prosocial behavior. Nevertheless, this community could not escape from being affected by the development that occurs around them. For example, the Orang Asli adolescents who live deep inside the jungle and in need for education have to stay behind at school where hostels are provided for them. This situation disclose them to the mainstream culture that is more individualistic in nature. By attending school, these Orang Asli adolescents are exposed to a variety of extra-curricular school activities as well as the scope of their communication is becoming increasingly prevalent among people from different races or the mainstream community. Therefore, looking to this situation, with their exposure to mainstream community, this study focused on the relations between the Orang Asli adolescent's attachment towards different social groups and prosocial value to their prosocial behavior tendencies.

\section{Method}

\section{Participants}

A total of 402 Orang Asli adolescents from 10 public Malaysian secondary schools of Perak and Pahang states were involved in this study. Both states are chosen as majority of the Orang Asli students were located in these states. Respondents were female $(n=245,60.90 \%)$ and male $(n=157$, $39.10 \%)$ aged 14 years old $(n=232,57.72 \%)$ and 16 years old ( $n=170,42.28 \%)$. Majority of the respondents (96.76\%) were from the Senoi tribe, $2.24 \%$ were Proto-Malays and $1.0 \%$ were Negritos. The Senoi Tribe live in the states of Perak and Pahang that explains for the majority of respondents were from this tribe (sub-ethnic). Meanhwile, as this study was conducted in school, therefore most of the respondents (77.1\%) stayed in school hostels provided by the JAKOA as their settlements are far from schools and in the remote jungle, while the remaining $22.9 \%$ of the respondents lived with their family especially those in the Cameron Higland area.

\section{Data Collection}

A quantitative approach using a self-administered questionnaire was adopted by using a crosssectional design method. For each 10 secondary schools involved in Perak and Pahang, students name lists were provided from the school counselors and classroom teachers weeks before data collection. From the list, students samples were selected using systematic random sampling. During the data collection, students were gathered in a classroom or the school hall. Self-administration questionnaire is used as it is more suitable because respondents are free to execute the task without any "interference" of the researcher. However, there were some students that have limited proficiency in Malay language and do not master basic literacy skills, therefore were unable to read and comprehend the task. Thus, the researcher with the help of a research assistant gathered these students in a group for one-to-one aid by reading and clarifying each item. 


\section{Measures}

Altruistic prosocial behavior. Altruistic prosocial behavior was measured by using the Prosocial Tendencies Measure-Revised (PTM-R) by Carlo and Randall (2002). The measurement consists of six subscales; alturistic, compliant, emotional, public, anonymous and dire. However, for this study; only two subscales were used which consists of altruistic and anonymous prosocial behaviors that represents the altruistic prosocial behavior by definition. Examples of the items are "I think one of the best thing about helping others is that it makes me look good" (altruistic), and "I think that helping others without them knowing is the best type of situation" (anonymous). Respondents were asked to rate to the statement on a four-point scale ranging from 1 (totally disagree) to 4 (totally agree). The reliability was $\alpha=.76$.

Parental attachment. Attachment to parents was measured using the Parental Attachment Questionnaire (PAQ) by Kenny, Griffiths, and Grossman (2005). The PAQ contains three scales: Affective Quality of Attachmnet, Parental Fostering of Autonomy, and Parental Role in Providing Emotional Support. However, for the purpose of this study, 7 items were selected to asses the Affective Quality of Attchment. Examples of items includes, "In general, my parents understand my problems and concern", and "During time spent together, my parents were persons for whom I felt a feeling of love" with indicators of 1 (Strongly agree) to 4 (Strongly disagree). The reliability was $\alpha=$ .78.

Peer attachment. Inventory of Parent and Peer Attachment (IPPA, Armsden \& Greenberg, 1987; Mavridis, 2014) was used to assess peer attachment. The IPPA was developed to assess adolescents' perceptions of the positive and negative affective/cogntitive dimensions or relationships with parents and close friends. 8 items from the inventory that particularly assess the students' attachment with their peer was used with a reliability of $\alpha=.79$. Examples of items are "My friends can tell when I'm upset about something", I like to get my friends' point of view on things I'm concerned about" with indicators of 1 (Strongly agree) and 4 (Strongly disagree).

School attachment. School connectedness Scale (SCS) by Furlong, O’Brennan, and You (1997) was used to measure adolescents' attachment to school environment. This scale is designed to measure the bond students' feel toward school and, as such, measures psychological and non academic, behavioral, and cognitive engagement. Examples of questions are "I feel proud to be in this school", I feel save and comfort in school", "I feel attached with people in my school, "Teachers in my school treat students fairly" with the response scales of 1 (Strongly disagree) to 4 (Strongly agree). The reliability is $\alpha=.78$.

Ethnic group attachement. Ethnic group attachment was measured using the Multigroup Mesure of Ethnic Identity (MEIM; Phinney, 1992). MEIM consists of 18 items assessing three aspects of ethnic identity: positive ethnic attitudes and sense of belonging, ethnic identity achievement, and ethnic behaviors or practices. Items are rated on a four-point scale from 1 (strongly disagree) to 4 (strongly agree). Examples of items includes "I am happy that I am a member of the group I belong to", "I have spent time trying to find more about my ethnic group, such as its hostory, traditions, and customs", "I participate in cultural practices of my own group, such as special food, music, or customs". The reliability was $\alpha=.77$.

Kindness. Values-in-action Inventory of Strengths for youth (VIA-youth; Peterson \& Seligman, 2004) was used to asess the extent to whoch adolescents valued and enjoyed helping and being kind to others. The VIA-youth assess 24 different values (e.g., bravery, creativity). As for the present study, 
10 items from the kindness subscale was adoped to examine participants prosocial value. Respondents rated statments based on a four-point scale with 1 (strongly agree) to 4 (strongly agree). Ther reliability was $\alpha=.84$.

\section{Results}

The study hypothesized that Orang Asli adolescents who reported higher scores in social attachments (i.e., parental, peer, school, and ethnic group) would also have higher kindness value. As shown in Table 1, prosocial value (kindness) was found to have positive significant correlation with parental attachment $(r=.370, p<.01)$ and ethnic group attachment $(r=.439, p<.01)$. The positive correlation coefficients indicate that the increase in the score for parental and ethnic group attachments are followed by the increase in kindness score. These findings imply that the Orang Asli adolescents who were more likely to attached strongly with their parents and ethnic group would contribute to the increasing of their kindness value. Meanwhile, negative significant relationship was reported between peer attachment and kindness $(r=-.32, p<.01)$ which indicates that the increase of peer attachment is followed by a decrease in the kindness value and vice versa. There was non-significant relationship reported between school attachment and kindness which indicates that attached to school does not give an impact on the participants' prosocial value. These results then reflects that the Orang Asli adolescents who were exposed to different environments may impact their kindness value.

Table 1: Correlation between Social Attachments and Prosocial Value $(\mathrm{N}=402)$

\begin{tabular}{lllllll}
\hline & Measure & $\mathbf{1}$ & $\mathbf{2}$ & $\mathbf{3}$ & $\mathbf{4}$ & $\mathbf{5}$ \\
\hline $\mathbf{1}$ & Parental Attachment & - & & & & \\
$\mathbf{2}$ & Peer Attachment & $-.319 * *$ & - & & & \\
& & $(.000)$ & & & & \\
$\mathbf{3}$ & School Attachment & .016 & -.006 & - & & \\
& & $(.752)$ & $(.909)$ & & & \\
$\mathbf{4}$ & Ethnic Group Attachment & $.384^{* *}$ & $-.351^{* *}$ & -.083 & - & \\
& & $(.000)$ & $(.000)$ & $(.098)$ & & \\
$\mathbf{5}$ & Kindness Value & $.370 * *$ & $-.352^{* *}$ & .009 & $.439 * *$ & - \\
& & $(.000)$ & $(.000)$ & $(.864)$ & $(.000)$ & \\
Note. ${ }^{*} \mathrm{p}<.05, * * \mathrm{p}<.01$ & & & & &
\end{tabular}

Meanwhile, Table 2 shows the correlation between group attachments and prosocial value on altruistic and egoistic prosocial behaviors. Result shows that parental $(r=.185, p<.01)$ and ethnic group $(r=.305, p<.05)$ attachments yielded positively significant relationship with altruistic prosocial behavior. Meanwhile, significant negative correlation was found between altruistic prosocial behavior and peer attachment $(r=-.153, p<.01)$. In contrary to that, parental and ethnic group attachments $\left(r_{\text {parental }}=-.140, p<.01 ; r_{\text {ethnic group }}=-.189, p<.01\right)$ show significant negative correlations to egoistic prosocial behaviors; however, peer attachment $(r=.190, p<.05)$ has a significant positive correlation with egoistic prosocial behavior. These indicate that adolescents who are more attached to their parents and ethnic group would highly likely adopt altruistic prosocial behavior instead of egoistic prosocial behavior tendencies, where the help would be given based on other intentions 
(e.g., emotional situations or helping for an approval). On the contrary, adolescents who were exposed and attached more to peers would have more egoistic prosocial behavior rather than altruistic prosocial behavior. In addition, similar to altruistic prosocial behavior, there was no significant correlation between egoistic prosocial behavior and school attachment.

For prosocial value (kindness), there were a positive significant relationship between prosocial value on altruistic and egoistic prosocial behaviors $\left(r_{\text {altruistic }}=.262, p<.01 ; r_{\text {egoistic }}=.306, p<.01\right)$. The positive correlation coefficient indicates that an increase in the kindness associate with increase in prosocial behavior tendencies regardless the intentions.

Table 2: Correlation between Altruistic and Egoistic Prosocial Behavior on Social Attachments and Prosocial Value (Kindness) ( $N=402)$

\begin{tabular}{|l|c|c|}
\hline Measure & $\begin{array}{l}\text { Altruistic Prosocial } \\
\text { Behavior }\end{array}$ & $\begin{array}{l}\text { Egoistic Prosocial } \\
\text { Behavior }\end{array}$ \\
\hline Social Attachments & $r$ (sig.) & $r$ (sig.) \\
\hline Parental Attachment & $.185^{* *}(.000)$ & $-.140^{* *}(.005)$ \\
Peer Attachment & $-.153^{* *}(.002)$ & $.190^{* *}(.003)$ \\
School Attachment & $-.066(.184)$ & $.073(.147)$ \\
Ethnic Group Attachment & $.305^{* *}(.000)$ & $-.198^{* *}(.000)$ \\
Prosocial Value & & \\
\hline Kindness & $.262^{* *}(.000)$ & $.306^{* *}(.000)$ \\
\hline
\end{tabular}

Note. ${ }^{*} p<.05,{ }^{*} p<.01$

\section{Discussion}

Social psychologists have identified several factors which shape the likelihood of help being offered. These include the number of people present (Latane \& Darley, 1970), the location of the incident (Milgram, 1970), and the costs of helping (Piliavin, Dovidio, Gaertner, \& Clark, 1981). However, in cultivating the helping environment, it is suggested that one's attachment to specific social group may enliven the prosocial act specifically among adolescents. Meanwhile, earlier studies have documented that kindness is the significant predictor for adolescents' altruistic prosocial behavior (Calderon-tena et al., 2011). Thus, this study explore the relations between social attachments and kindness on one's intention to help that is either underlies by altruistic or egoistic prosocial behavior intentions.

Specifically, this study opts to examine the association between group attachments (i.e., parental, peer, school and ethnic group) and prosocial value (kindness) on prosocial behavioral tendencies (i.e, altruistic and egoistic prosocial behaviors). As kindness value contribute to prosocial behavior, therefore, it is crucial to understand its relation to the types of social attachments that contribute to one's prosocial intentions. Specifically, this study shows that parental and ethnic group attachments positively associated to kindness value. On the other hand, attachment to peer which in this context is the school's friends may reduce the kindness value. Moreover, there is no relationship on kindness value nor prosocial behavior intentions when associate to school attachment. Somehow, as school is 
a place where prosocial should be nurtured and cultivate, this study shows the opposite particularly among the Orang Asli students. This can be explained by the nature of the Orang Asli people. Through observation, these Orang Asli adolescents are those that came to school from the remote jungle. Therefore, exposing them to the school which located at the town area will affect their socioemotional and psychological well-being. Being far from their tribes and families makes them having the feeling of inferiority and time to adapt, thus explains the non-significant result of the school attachment.

\section{Attachment and prosocial value among Orang Asli Adolescents}

In discussing further, parent attachment in particular, or the secure, positive, and warm relationship between parent and child, has been linked to valued prosocial behaviors in adolescents (Eberly \& Montemayor, 1998). Researchers suggest that a healthy attachment between parent and child contributes to the development of competence and social skills, as well as the development of empathy and understanding of another's situation, which in turn have also been found to promote prosocial value. In the context of Orang Asli where they are quite heterogeneous in multiple ways, many Orang Asli family's value and emphasize familial interdependence and have been found to be less conflictual compared to other mainstream communities in Malaysia (Dentan, 2001). It is likely that a close and warm relationship between parent and child also positively influence prosocial values among Orang Asli adolescents. It has been noted that Orang Asli families tend to exhibit unique characteristics, such as the reliance of family members. Specifically, this includes the flexible assignment of roles among family members and reliance on extended family for support.

According to Cornwell and Eggebeen (1996), during the adolescents, peer influence increases while interaction among family members diminishes. Friends and cliques, as a social context, is no less important to adolescent. Therefore, the peer group is a prominent agent of socialization of achievement, ritualistic and behavior (Ryan \& Deci, 2000). Attachment with school and peers provide adolescents with a variety of suggestions and choices to be contemplated and acted on many things. They also have an impact on adolescents' response on their evaluation through retention or changes in motivation and involvement in an activity (Eccles, Wigfield, \& Schiedele, 1998). Therefore, attachment with peers might also serve as a training platform for antisocial practices and misdeeds. Among the Orang Asli adolescents, the cause of the decreasing level of prosocial value on their attendance to school and dealing with peers especially from the mainstream communities might be caused by the bad treatment they received in school and among peers (as for example taunting and bullying). Furthermore, other factors that may lead to the decreasing of the kindness value among the Orang Asli students may be due to their attachment to peers, not interested in the school curriculum and some of them are fed up with being scolded by teachers. Moreover, it is also reported that these students would prefer helping their parents at their settlements and among them are too shy to go to school in towns. Knowing Orang Asli as a group that is generally lacking in the sense of motivation and self-esteem, the situation they are facing in school and their relationship with peers would bring them towards the decreasing of kindness value toward others. Orang Asli have a strong non-violent image of themselves and they proclaim themselves to be non-violent people who do not get angry or those who would hit others (Dentan, 2001). A self-image that allows aggression would contradict their definition or virtue and therefore brings to a decrease in prosocial values as they were in school or when interacting with peers. 


\section{Attachment on prosocial behavior tendencies among Orang Asli}

In an Orang Asli community, its members have a strong bond among themselves and value sharing, group solidarity, mutual dependence, and peace that would strengthen the altruistic prosocial behavior among them (Dentan, 2001). Altruistic prosocial behavior which commonly takes place in situations where the helping behavior is given without any intention or demand for reward, is widely nurtured among the Orang Asli younger generations. There is an existence of mutual dependence between members of the community in terms of sharing and helping, and these behaviors eventually maintains the attachment within the group and the unity of the community.

As for peer attachment, adolescents who act prosocially are relatively well adjusted and have better peer relationships as compared to those who act less prosocially (Clark \& Ladd, 2000). The findings of this current study are incongruent to the findings of previous studies (Guzman, Carlo, \& Edwards, 2008) which suggest that adolescents who have higher companionship with their friends (peers) tend to adopt more altruistic prosocial behavior. Even though this study came out with a different finding where Orang Asli students reported to be egoistic in prosocial acts, this could be explained by the level of attachment among this community to their peers. In this study, their attachment to peers which considered as low might be the factor as to why this community reacts in helping others in terms of egoistic prosocial behavior where helping is given in selected situations. Explaining from the Social Exchange Theory, these findings support the perspective by indicating that communal relationships exist in the adolescents' attachment to parent and ethnic group where it brings to a more altruistic prosocial behavior rather than assist with other intention as reported through their attachment to peer group.

\section{Prosocial Value on Prosocial Behavior Tendencies}

Although the broad distinction between collectivist and individualist cultures is overly simplistic and may obscure intracultural variability, several researchers have suggested that adolescents in more collectivist cultures are more empathic, altruistic, helpful, or cooperative than adolescents in individualist cultures (Pilgrim \& Reuda-Riedle, 2002). This may be due to the collectivist cultures' deemphasizing of individual needs or goals in lieu of attention to the needs of the broader community and the promotion of greater involvement of adolescents in other-oriented activities. This then supported the current findings among the Orang Asli adolescents where they came from a culture that avoids sensitive issues, embrace honesty and values altruistic and acts of kindness in their community. Despite having prosocial value in relation to egoistic prosocial behavior, it might be due to the effects of the socio-psychological environments they are facing with other people's acceptance of them and the treatment they received, as well as their perception towards outsiders. Moreover, in a collectivist culture, they tend to have fewer interpersonal relationship with other communities but once they do, it is typically stable and long-lasting. Therefore, it makes sense on the existence of prosocial value in egoistic proscocial behavior where the helping behavior that comes from the value of kindness makes these Orang Asli adolescents to still lend a helping hand even though there might be other intentions to the help given.

\section{Conclusion}

The glaring absence of literature about the relationship between attachment and prosocial value on prosocial behavior has been addressed in this study particularly among the Orang Asli adolescent. By 
rights, this community's' prosocial behavior tendencies may propose different result compare to the mainstream community as per their attitude on the social attachment and how it may contribute to their prosocial acts. Specifically, this study emphasized on the tendencies one's to act in altruistic or egoistic prosocial behaviors that merely depends on their attachment to a particular group and moreover will also affect their prosocial value. This overall indicates that higher internal regulation of kindness and attached to significant others (i.e., parental and ethnic group) were more likely to report prosocial tendencies that de-emphasized themselves (altruistic prosocial behavior), and were less likely to report tendencies for the approval of others (egoistic prosocial behaviors). This is important to put into highlight as by knowing that to whom or which groups that one's attached with will affect their intention to help, thus may enlighten further research on the importance to nurture and cultivate helping acts in those particular entity. Essentially, it is therefore encouraging to see that prosocial behavior can be effectively supported and that prosocial development can be nurtured.

\section{References}

Armsden, G. C., \& Greenberg, M. T. (1987). The inventory of parent and peer attachment: Individual differences and their relationship to psychological well-being in adolescence. Journal of youth and adolescence, 16(5), 427-454.

Barr, J. J., \& Higgins-D'Alessandro, A. (2007). Adolescent empathy and prosocial behavior in the multidimensional context of school culture. The Journal of Genetic Psychology, 168(3), 231250.

Batson, C. D., \& Oleson, K. C. (1991). Current status of the empathy-altruism hypothesis. In M. S. Clark (Ed.), Review of personality and social psychology, Vol. 12. Prosocial behavior (p. 62-85).

Brief, A., \& Motowidlo, S. J. (1986). Prosocial organizational behaviors. The Academy of management Review, 11(4), 710-725.

Calderon-Tena, C. O., Knight, G. P., \& Carlo, G. (2011). The socialization of prosocial behavioral tendencies among Mexican American adolescents: The role of familism values. Cultural Diversity and Ethnic Minority Psychology, 17(1), 98.

Carlo, G., \& Randall, B. A. (2002). The development of a measure of prosocial behaviors for late adolescents. Journal of youth and adolescence, 31(1), 31-44.

Carlo, G., Hausmann, A., Christiansen, S., and Randall, B. A. (2003). Sociocognitive and behavioral correlates of a measure of prosocial tendencies for adolescents. The Journal of Early Adolescence. 23, 107-134.

Carlo, G., Knight, G. P., McGinley, M., \& Hayes, R. (2011). The roles of parental inductions, moral emotions, and moral cognitions among Mexican American and European American Early Adolescents. The Journal of Early Adolescence, 31(6), 757-781.

Clark, K. E., \& Ladd, G. W. (2000). Connectedness and autonomy support in parent-child relationships: Links to children's socioemotional orientation and peer relationships. Developmental psychology, 36(4), 485.

Cornwell, G. T., Eggebeen, D. J., \& Meschke, L. L. (1996). The changing family context of early adolescence. The Journal of Early Adolescence, 16(2), 141-156.

Davis, M. H. (1994). Social psychology series. Empathy: A social psychological approach. Westview Press. 
De Waal, F. B., \& Brosnan, S. F. (2006). Simple and complex reciprocity in primates. In Cooperation in primates and humans (pp. 85-105). Springer, Berlin, Heidelberg.

Dentan, R. K. (2001). Ambivalences in child training by the Smeai of Peninsular Malaysia and other peoples.

Dovidio, J. F., Piliavin, J. A., Schroeder, D. A., \& Penner, L. A. (2017). The social psychology of prosocial behavior. Psychology Press.

Eberly, M. B., \& Montemayor, R. (1998). Doing good deeds: An examination of adolescent prosocial behaviour in the context of parent-adolescent relationships. Journal of Adolescent Research, 13(4), 403-432.

Eccles, J. S., Wigfield, A., \& Schiefele, U. (1998). Motivation to succeed. In W. Damon \& N. Eisenberg (Ed.), Handbook of child psychology: Social, emotional, and personality development ( $p$. 1017-1095). John Wiley \& Sons, Inc.

Eisenberg, N., \& Eggum, N. D. (2009). Empathic responding: Sympathy and personal distress. The social neuroscience of empathy, 6, 71-83.

Eisenberg, N., \& Fabes, R. A. (1991). Prosocial behavior and empathy: A multimethod developmental perspective. In M. S. Clark (Ed.), Review of personality and social psychology, 12, 34-61.

Eisenberg, N., \& Mussen, P. H. (1989). Cambridge studies in social and emotional development. The roots of prosocial behavior in children. Cambridge University Press.

Flook, L. F., Goldberg, S. B., Pinger, L., \& Davidson, R., (2015). Promoting prosocial behaviour and selfregulatory skills in preschool children through a kindfulness-based kindness curriculum. Developmental Psychology Journal, 51(1), 44-51.

Furlong, M. J., O'brennan, L. M., \& You, S. (2011). Psychometric properties of the Add Health School Connectedness Scale for 18 sociocultural groups. Psychology in the Schools, 48(10), 986-997.

Guzman, M.R., Carlo, G., \& Edwards, C.P. (2008). Prosocial behaviors in context: Examining the role of children's social companions. International Journal of Behavioral Development, 32, 522 530.

Hamalainen, H., \& Tanskanen, A. O. (2017). Intergenerational transfers towards adult children and elderly parents. DOI: $10.13140 /$ RG.2.2.28378.44488/1.

Henry, K. L., \& Slater, M. D. (2007). The contextual effect of school attachment on young adolescents' alcohol use. Journal of school health, 77(2), 67-74.

Hoffman, M. L. (1981). Is altruism part of human nature? Journal of Personality and Social Psychology, 40(1), 121-137.

Homans, G. C. (1958). Social Behaviour as Exchange. American Journal of Sociology, 63, 6, 597-606.

House, B. R., Silk, J. B., \& Clark, H. (2013). Ontogeny of prosocial behavior across diverse societies. Proceedings of the National Academy of Sciences, 110(36).

Kenny, M. E., Griffiths, J., \& Grossman, J. (2005). Self-image and parental attachment among late adolescents in Belize. Journal of adolescence, 28(5), 649-664.

Knight, G. P., Bernal, M. E., \& Carlo, G. (1995). Socialization and the development of cooperative, competitive, and individualistic behaviors among Mexican American children. In E. E. Garcia, \& B. McLaughlin (Eds.), Meeting the challenge of linguistic and cultural diversity in early childhood (pp. 85-102). New York, NY: Teachers College Press. 
Knight, G. P., Cota, M. K., \& Bernal, M. E. (1993). The socialization of cooperative, competitive, and individualistic preferences among Mexican American children: The mediating role of ethnic identity. Hispanic Journal of Behavioral Sciences, 15, 291-309.

Krebs, D. L. (2015). Prosocial behavior. In Evolutionary perspectives on social psychology (pp. 231242). Springer, Cham. Latané, B., \& Nida, S. (1981). Ten years of research on group size and helping. Psychological bulletin, 89(2), 308.

Lawford, H., Pratt, M. W., Hunsberger, B., \& Pancer, M. S. (2005). Adolescent generativity: A longitudinal study of two possible contexts for learning concern for future generations. Journal of Research on Adolescence, 15(3), 261-273.

Layous, K., Nelson, S. K., Oberle, E., Schonert-Reichl, K. A., \& Lyubomirsky, S. (2012). Kindness counts: Prompting prosocial behavior in preadolescents boosts peer acceptance and wellbeing. PloS one, 7(12), e51380.

Mavridis, S. (2014). The Human Right to The City. Multilingual Academic Journal of Education and Social Sciences, 2(2), 75-91.

Mikulincer, M., \& Shaver, P. R. (2015). The psychological effects of the contextual activation of security-enhancing mental representations in adulthood. Current Opinion in Psychology, 1, 18-21.

Nie, Y., Li., J., \& Vazsonyi, A. T. (2016). Self-control mediates the association between parental attachment and prosocial behaviors among Chinese adolescents. Personality and Individual Differences, 96. DOI: 10.1016/j.paid.2016.02.077

Oldfield, J., Humphrey, N. \& Hebron, J. (2015). The Role of Parental and Peer Attachment Relationships and School Connectedness in Predicting Adolescent Mental Health Outcomes. Child and Adolescent Mental Health, 21(1).

Park, J. H., \& Schaller, M. (2005). Does attitude similarity serve as a heuristic cue for kinship? Evidence of an implicit cognitive association. Evolution and Human Behavior, 26(2), 158-170.

Penner, L. A., Dovido, J. F., \& Piliavin, J. A. (2005). Prosocial behavior: Multilevel perspectives. Annual Review of Psychology, 56(1), 365-392.

Peterson, C., \& Seligman, M. E. (2004). Universal virtues? Lessons from history.

Phinney, J. S. (1992). The multigroup ethnic identity measure: a new scale for use with diverse groups. Journal of Adolescent Research, 7(2), 156-172.

Pilgrim, C., \& Rueda-Riedle, A. (2002). The importance of social context in cross-cultural comparisons: First graders in Colombia and the United States. The Journal of Genetic Psychology, 163(3), 283-295.

Piliavin, J. A., Dovidio, J. F., Gaertner, S. L., \& Clark, R. (1981). Emergency interventions, New York, Academic Press.

Ryan, R. M., \& Deci, E. L. (2000). Self-determination theory and the facilitation of intrinsic motivation, social development, and well-being. American psychologist, 55(1), 68.

Schwartz, S. J., Zamboanga, B. L., \& Jarvis, L. H. (2007). Ethnic identity and acculturation in Hispanic early adolescents: Mediated relationships to academic grades, prosocial behaviors, and externalizing symptoms. Cultural Diversity and Ethnic Minority Psychology, 13(4), 364-373.

Tajfel, H. (1981). Human groups and social categories: Studies in social psychology. Cup Archive.

Triandis, H. C. (1996). The psychological measurement of cultural syndromes. American psychologist, 51(4), 407. 
INTERNATIONAL JOURNAL OF ACADEMIC RESEARCH IN BUSINESS AND SOCIAL SCIENCES

Vol. 10, No. 16, Youth and Community Wellbeing: Issues, Challenges and Opportunities for Empowerment V2. 2020, E-ISSN: 2222-6990 @ 2020 HRMARS

Van Hoorn, J., Van Dijk, E., Meuwese, R., Rieffe, C., \& Crone, E. A. (2016). Peer influence on prosocial behavior in adolescence. Journal of Research on Adolescence, 26(1), 90-100.

Yates, M., \& Youniss, J. (1996). A developmental perspective on community service in adolescence. Social Development, 5(1), 85-111. 